Research Article

\title{
Resurgence of diphtheria: clinical profile and outcome - a retrospective observational study
}

\author{
Basavaraja G.V., Pooja Gujjal Chebbi, Siddharth Joshi*
}

Department of Pediatric Medicine, Indira Gandhi Institute of Child Health, Bangalore, Karnataka, India

\author{
Received: 08 December 2015 \\ Revised: 12 December 2015 \\ Accepted: 22 December 2015 \\ *Correspondence: \\ Dr. Siddharth Joshi, \\ E-mail:drsidj@gmail.com
}

Copyright: ( ) the author(s), publisher and licensee Medip Academy. This is an open-access article distributed under the terms of the Creative Commons Attribution Non-Commercial License, which permits unrestricted non-commercial use, distribution, and reproduction in any medium, provided the original work is properly cited.

\begin{abstract}
Background: Despite the availability of antitoxin and antibiotics, the mortality rate for diphtheria remains high. In the pre-vaccination era, diphtheria was a leading cause of childhood mortality. With the introduction of routine childhood immunization, paediatric care and improved hygiene status the disease has been almost completely eradicated in many developed countries. On the contrary developing countries, still account for $80-90 \%$ of the global burden. The present paper is a retrospective study in an attempt to highlight the problems faced by developing countries in tackling the menace of diphtheria and also to examine the outcome and clinical profile of diphtheria in children.

Methods: Study is based on the retrospective analysis of the records available from January 2015 to December 2015 at a tertiary referral hospital, Indira Gandhi Institute of Child Health. The data was obtained from the hospital medical records section by searching for cases diagnosed as Diphtheria based on WHO criteria for diagnosing Diphtheria. The data was analysed retrospectively with respect to demographic details, clinical features, immunization status, pseudo membrane score, complications and mortality.

Results: Incidence in those over 5 years was $25.8 \%$. Only $48.3 \%$ cases were fully immunized. The case fatality rate was $41 \%$.

Conclusions: In conclusion, the occurrence of diphtheria even in those immunized highlights the flaws in the present immunization program.
\end{abstract}

Keywords: Diphtheria, Resurgence, Anti diptheric serum, Epidemic, Epidemiological surveillance

\section{INTRODUCTION}

Diphtheria is a potentially fatal acute disease caused by Corynebacterium diphtheriae. In the pre-vaccination era, diphtheria was a leading cause of childhood mortality., Forty percent of the cases occurred in children below 5 years and $70 \%$ below 15 years of age. ${ }^{1}$ The disease has been almost completely eradicated in many developed countries and in many European countries no cases have been reported for almost a decade and in the USA only 45 cases were reported during 1980-1995. ${ }^{3}$
On the contrary, in developing countries, although the incidence has drastically declined, still account for 80 $90 \%$ of global burden. Disease in these countries affects both children and young adults. ${ }^{2}$ However, a resurgence of the disease has been observed in these countries, largely attributed to waning vaccine immunity in adults and importation of cases from the endemic developing world. The situation faced by us in the developing countries is different. Diphtheria still remains endemic with increase in the fulminant complications and mortality in the last two decades, especially in children above 5 years. Factors like inadequate vaccine coverage, poor socio-economic standards, overcrowding, delayed 
reporting to hospital, non-availability and delay in administration of antitoxin further contribute to the high mortality. The present paper is a retrospective study is an attempt to highlight the problems faced by developing countries in tackling the menace of diphtheria and also to examine the outcome and predictors of mortality of diphtheria in children receiving intensive care.

Aims of the study were:

1. To identify the mortality and morbidity trends of diphtheria.

2. To study the immunization status of affected children.

3. To know the microbiological confirmation rates.

4. To study the data regarding antidiphtheritic serum (ADS) administration.

5. Difficulties in managing a proven case.

\section{METHODS}

The present study is based on the retrospective analysis of the records available from January 2015 to December 2015 at a tertiary referral hospital, Indira Gandhi Institute of Child Health. The data will be obtained from the hospital medical records section by searching for cases diagnosed as Diphtheria. The data will be analysed retrospectively with respect to demographic details, clinical features, immunization status, pseudo membrane score, complications and mortality. Several variables will be compared among the survivors and non-survivors to define the predictors of outcome. Outcome is defined as either recovered or died. Cases studied will include suspected, probable and confirmed cases of diphtheria as per the WHO definition guidelines. ${ }^{4}$

All children with a clinical suspicion of diphtheria will be started on parenteral crystalline penicillin in the dose of $50,000 \mathrm{U}-1,00,000 \mathrm{U}$ in 4 divided doses. Antidiphtheritic serum (ADS) will be given in a single dose as recommended depending on the site and extent of disease. Throat swab for Albert's stain and culture will be sent in all, at the time of admission. Patients with anticipated/established features of any complications like airway obstruction, myocarditis, renal failure and thrombocytopenia will be shifted to PICU for monitoring and management.

\section{RESULTS}

Eight patients $(25.8 \%)$ were less than 5 years and twenty three patients $(74.1 \%)$ were over 5 years. Fifteen patients $(48.3 \%)$ were males and sixteen $(51.6 \%)$ were females.

\section{Morbidity and mortality}

Case fatality rate: There were 13 deaths with a case fatality rate of $41 \%$. Among the 19 deaths, 9 cases were that of children over the age of 5 years.

\section{Immunization status of the affected children}

Fifteen (48.3\%) were immunized fully and 15 cases $(48.3 \%)$ were non-immunized. Incomplete immunization has been considered as non-immunized status.

\section{Bull neck}

Out of 31 children, $14(45.16 \%)$ children presented with bull neck at presentation. Out of 14 children with bull neck $10(71.4 \%)$ children succumbed to death.

\section{Myocarditis}

Out of 31 children, $13(41.9 \%)$ children developed myocarditis. Out of 13 children who developed myocarditis, $10(76.9 \%)$ children succumbed to death. 7 $(53.8 \%)$ children developed myocarditis in the first week of the illness.

\section{Microbiological confirmation rates}

Albert staining was performed in 31 cases of which 10 $(32.2 \%)$ cases were positive. Culture was performed in 31 cases of which five were positive $(16.1 \%)$.

\section{Antidiphtheritic serum (ADS) administration}

ADS were administered in 31cases. In 11 of these 52 cases the outcome was not known. Outcome was analyzed for ADS administration leaving out the cases where outcome was not known.

Table 1: Clinical characteristics of 31 patients with diphtheria.

\begin{tabular}{|ll|}
\hline Age & \\
\hline$>5$ years & $23(74.1 \%)$ \\
\hline$<5$ years & $8(25.8 \%)$ \\
\hline Sex & \\
\hline Male & $15(48.3 \%)$ \\
\hline Female & $16(51.6 \%)$ \\
\hline Immunization status & \\
\hline Immunized & $15(48.3 \%)$ \\
\hline Not immunized & $15(48.3 \%)$ \\
\hline Bull neck & $14(45.16 \%)$ \\
\hline Death & $19(61.2 \%)$ \\
\hline Myocarditis & $13(41.9 \%)$ \\
\hline Albert staining & $10(32.2 \%)$ \\
\hline Culture positivity & $5(16.1 \%)$ \\
\hline
\end{tabular}

\section{DISCUSSION}

In the last 5 years there is a resurgence of diphtheria and India has accounted for 3,123 cases of the total of 4,053 cases $(77.05 \%)$ reported in the world in 2010 . There have been numerous reports from different parts of India. The microbiologically confirmed cases range from 7 to $1 \%$ in 
various studies. ${ }^{5,6}$ However in a retrospective study conducted at Delhi where initially microbiologically confirmed cases was $26.3 \%$ in 1998 rose to $64.9 \%$ after adopting WHO recommended methods of detection. ${ }^{7}$ However, still many places in India lack basic diagnostic facilities. Many times the throat swab is not taken from the representative area which may give negative results. Only $48.3 \%$ of the patients in the present study were immunized for diphtheria and the rest were either nonimmunized. As in the present study, cases occurring even in the immunized individuals highlight the defect in the whole process of immunization. There is a significant drop out between the 1st and 3rd dose of OPV/DPT in different parts of India. ${ }^{8}$ There has been no provision to trace the vaccine drop outs. ${ }^{7,9}$ Poor immunization coverage has been attributed to the poor vaccination services, low awareness among parents and inaccessibility of health centres. ${ }^{9,10}$

Many authors have highlighted deteriorating health infrastructure, adoption of an alternative schedule of few doses of low antigenic strength and administration of the second childhood booster at 9 years instead of 6 years. ${ }^{1}$ Any drop in childhood immunization coverage may trigger an epidemic and hence adult booster dosages may be necessary. In some situations child may not be vaccinated despite being in contact with the health facility and is termed as "missed opportunities". This might have resulted from short supply of vaccine, poor clinic organization, non availability of immunization services on all days of a week, inadequate screening for immunization status of the children visiting the health facility, not opening a multidose vial if enough children are not present and delaying or postponing vaccination for minor childhood illnesses.

Minimum immunization coverage of $90 \%$ in children and $75 \%$ in adults is required to prevent spread of diphtheria. ${ }^{12}$ Overcrowding and migrant population with low immunization coverage are the potential risk factors. ${ }^{13}$ The proportion of children immune to diphtheria as well as booster coverage was low among muslim population. ${ }^{14}$ This has been attributed to either a poor offer of vaccine by health services or poor demand of vaccine in the community. This fact was also supported by another study which found $70 \%$ to be Muslims among 2,685 cases of diphtheria and had 3 times higher risk than other communities. ${ }^{15}$

There does not exist any surveillance system for vaccine preventable diseases except for poliomyelitis in India. While polio causes debility, diphtheria can be dangerous and associated with high mortality. Many families accept pulse polio as a substitute for routine immunization in the absence of adequate awareness. ${ }^{7}$ Statistics on diphtheria was taken essentially from primary health centre, which would only be a small fraction of the total. There is a need for simple, practical, inexpensive, real time disease surveillance, using the district as a unit, covering both public and private sector medical care establishments. ${ }^{16}$
Isolation of diphtheria cases is poor and ranged from 0 to $14.7 \%$ but increased from $3 \%$ in 1995 to $36 \%$ in $2001 .^{17,18}$ As secondary attack rate is very high all cases needs to be isolated and their family members thoroughly examined. The school where the child studied need to be examined for the possible exposed individuals. There is an age shift of occurrence recently and 40-45\% was above the age of 5 years..$^{5}$ This was initially noted in Russian epidemic and China outbreak but however for the first time in India similar observations were made in a study by Sharma. ${ }^{19}$ The present study supports the study with $74.1 \%$ of the patients who are above the age of 5 years. Case fatality rate in the present study was $41 \%$ where as it ranged from 32 to $56.3 \%$ in different centers in north India, and $42.9 \%$ in west India. ${ }^{8,17,20,21}$ This higher case fatality was attributed to non-availability of antitoxin in India. 6,17,20,22 This may also be due to delay in diagnosing the cases. Antibiotics still play a very important role in the mild forms of diphtheria. However, drug resistance has been observed to Penicillin, Chloramphenicol, Erythromycin, Tetracycline and Ampicillin in various studies in India. ${ }^{23,25}$ Before the introduction ADS, case-fatality rates from some diphtheria outbreaks reached or exceeded $50 \% .^{26}$ However with introduction of antitoxin, morbidity and mortality have come down drastically in majority of the developed countries. Although ADS needs to be given on strong suspicion of diphtheria even without waiting for microbiological confirmation, it was given only in eight of our cases and was largely due to the non-availability and cost factor. It is important that all cases are notified and health authorities take suitable measures by concentrating on the community where the case was reported.

\section{CONCLUSION}

Diphtheria morbidity and mortality continues to be high in India. There is an age shift in the occurrence of diphtheria increasingly over 5 years of age.

\section{Funding: No funding sources \\ Conflict of interest: None declared}

Ethical approval: The study was approved by the Institutional Ethics Committee

\section{REFERENCES}

1. Vitek CR, Wharton M. Diphtheria in the former Soviet Union: reemergence of a pandemic disease. Emerg Infect Dis. 1998;4:539-50.

2. Galazka AM, Rabertson SE. Diphtheria: changing patterns in the developing world and industrialized world. Eur J Epidemiol. 1995;11:107-17.

3. Vitek CR, Wenger J. Diphtheria. Bull WHO 1998;76(Suppl 2):129-30.

4. Begg N. Diphtheria-manual for the management and control of diphtheria in the European region. WHO Publication, Copenhagen, 1994. 
5. Ray SK, Das Gupta S, Saha I. A report of diphtheria surveillance from a rural medical college hospital. J Indian Med Assoc. 1998;96(8):236-8.

6. Jayashree M, Shruthi N, Singhi S. Predictors of outcome in patients with diphtheria receiving intensive care. Indian Pediatr. 2006;43(2):155-60.

7. Nair TN, Varughese E. Immunization coverage of infants-rural-urban difference in Kerala. Indian Pediatr. 1994;31(2):139-43.

8. Department of Family Welfare Annual Report. Ministry of Health and Family welfare, Government of India, New Delhi. 1998-1999:83-71.

9. Singh J, Ichhpujani RL, Prabha S. Immunity to diphtheria in women of child bearing age in Delhi in 1994: evidence of continued Corynebacterium diphtheriae circulation. Southeast Asian J Trop Med Public Health. 1996;27(2):274-8.

10. Mukherjee B, Ray SK, Kar M, Mandal A, Mitra J, Biswas R. Coverage evaluation surveys amongst children in some blocks of West Bengal. Indian J Public Health. 1990;34(4):209-14.

11. Nivsarkar N, Pathak AA, Thakar YS, Saoji AM. Study of diphtheria antibody levels in healthy population. Indian J Pathol Microbiol. 1994;37(4):421-4.

12. Icchpujani RL, Grover SS, Joshi PR, Kumari S, Verghese T. Prevalence of diphtheria and tetanus antibodies in young adults in Delhi. J Commun Dis. 1993;25(1):27-9.

13. Singhal T, Lodha R, Kapil A, Jain Y, Kabra SK. Diphtheria-down but not out. Indian Pediatr. 2000;37(7):728-38.

14. Murhekar MV, Bitragunta S, Hutin Y, Chakravarty A, Sharma HJ, Gupte MD. Immunization coverage and immunity to diphtheria and tetanus among children in Hyderabad, India. J Infect. 2009;58(3):191-6.

15. Bitragunta S, Murhekar MV, Hutin YJ, Penumur PP, Gupte MD. Persistence of diphtheria, Hyderabad, India, 2003-2006. Emerg Infect Dis 2008;14(7):1144-6.

16. John TJ. Resurgence of diphtheria in India in the $21^{\text {st }}$ century. Indian J Med Res. 2008;128(5):669-70.

17. Lodha R, Dash NR, Kapil A, Kabra SK. Diphtheria in urban slums in north India. Lancet. 2000;55(9199):204.

18. Sharma NC, Tiwari KN, Panda RC, Dhillon R. Diphtheria status in India and data from a sentinel centre in Delhi, India. In: Proceeding of the 7 th international meeting of the European laboratory working group on diphtheria (ELWGD), Vienna, Austria. 2002;12-4.

19. Sharma NC, Banavaliker JN, Ranjan R, Kumar R. Bacteriological and epidemiological characteristics of diphtheria cases in and around Delhi-a retrospective study. Indian J Med Res. 2007;126(6):545-52.

20. Singh J, Harit AK, Jain DC et al (1999) Diphtheria is declining but continues to kill many children: analysis of data from a sentinel centre in Delhi, 1997. Epidemiol Infect. 1999;123(2):209-15.

21. Patel UV, Patel BH, Bhavsar BS, Dabhi HM, Doshi SK. A retrospective study of diphtheria cases, Rajkot, Gujarat. Indian J Med Res. 2004;29:161-3.

22. Dittmann S, Wharton M, Vitek C. A successful control of epidemic diphtheria in the states of the former union of Soviet Socialist Rupublics: lessons learned. J Infect Dis. 2000;181(Suppl 1):510-22.

23. Ayyagari A, Venugopalan A, Ray SN. Studies on diphtheria infection in and around Delhi. J Indian Med Assoc. 1975;65(12):328-31.

24. Dutta JK, Ayyagari A, Gautum AP, Chadha SK, Ray SN. A comparative study of bacteriologically probed and clinically diagnosed (culture negative) cases of diphtheria. J Indian Med Assoc. 1976;67(11):241-5.

25. Ayyagari A, Venugopalan A, Ray SN. Studies on cutaneous diphtheria in and around Delhi. Indian J Med Res. 1977;65(1):43-50.

26. Weekly epidemiological record (2006, Jan 20) WHO, Geneva, pp 24-32. http://www.who.int/wer/2006/wer8103.pdf. Updated 2011, Jan 7; cited 2011, Sep 4.

27. Nandi R, De M, Browning S, Purkayastha P, Bhattacharjee AK. Diphtheria: the patch remains. J Laryngol Otol. 2003;117(10):807-10.

28. Dravid MN, Joshi SA. Resurgence of diphtheria in Malegaon and Dhule regions of north Maharashtra. Indian J Med Res. 2008;127(6):616-7.

29. Immunization surveillance, assessment and monitoring - date, statistics and graphics by subject (2011, Sep 5) WHO Publication, Geneva. http://www.who.int/immunization_monitoring/data/d ata_subject/en/. Updated 2011, July 22; Cited 2011, Sep 21 .

Cite this article as: Basavaraja GV, Chebbi PG, Joshi S. Resurgence of diphtheria: clinical profile and outcome - a retrospective observational study. Int J Contemp Pediatr 2016;3:60-3. 